\title{
Community innovation in hazardous materials management: progress in implementing SARA Title III in the United States
}

\author{
Michael K. Lindell ${ }^{\mathrm{a}}$, Ronald W. Perry ${ }^{\mathrm{b}, *}$ \\ ${ }^{a}$ Hazard Reduction and Recovery Center, Texas A\&M University, College Station, TX 77843-3137, USA \\ b School of Public Affairs, Arizona State University, Tempe, AZ 85287-0603, USA
}

\begin{abstract}
Title III of the Superfund Amendments and Reauthorization Act (SARA Title III) established a new federal approach to managing toxic chemical hazards. This legislation required industry to disclose the type and quantity of such chemicals and also required the establishment of state and local government organizations to receive those data, evaluate community vulnerability, develop local emergency response plans, and communicate with the public. This paper reviews the law's historical context and empirical studies of its implementation. The available evidence suggests that significant progress has been made in reducing chemical hazards but there is considerable variation across jurisdictions in the effectiveness of the law's implementation. The research results reviewed here suggest a variety of ways in which SARA Title III implementation can be improved. (C) 2001 Elsevier Science B.V. All rights reserved.
\end{abstract}

Keywords: SARA Title III; LEPC; SERC; Toxic chemicals; Emergency planning

\section{Introduction}

Title III of the Superfund Amendments and Reauthorization Act (SARA Title III), also known as the Emergency Planning and Community Right to Know Act of 1986, represents a major innovation in communities' management of toxic chemical hazards. This regulation has two principal provisions for reducing the threat of catastrophic chemical accidents. First, it mandates industry disclosure of data on the types and quantities of extremely hazardous substances (EHSs) produced, used, or stored onsite. Second, it requires that state (State Emergency Response Commission - SERC) and local (Local Emergency Planning

\footnotetext{
* Corresponding author. Tel.: +1-480-965-3978; fax: +1-480-965-9248.

E-mail address: ron.perry@asu.edu (R.W. Perry).
} 


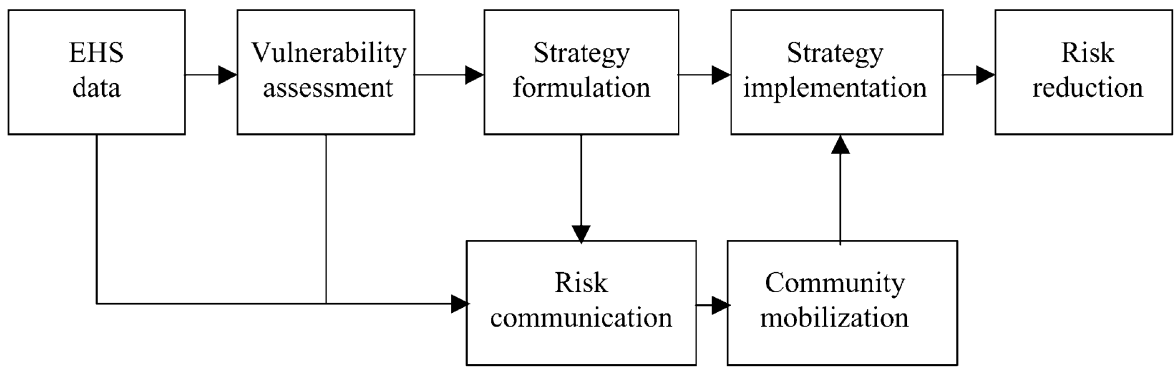

Fig. 1. The SARA Title III model of community toxic chemical hazard management.

Committee - LEPC) organizations be established to receive, evaluate, and act on that data. As Fig. 1 indicates, LEPCs are to use the EHS data to conduct vulnerability assessments that identify areas of the community that would be affected by chemical releases [46]. In turn, vulnerability assessments provide a basis to formulate a strategy that enables the community to manage this vulnerability. SARA Title III explicitly required toxic chemical emergency response plans as part of every community's strategy, but other actions such as onsite (e.g. source reduction and source substitution) and offsite (e.g. land use controls) hazard mitigation also can be included. The LEPC then can implement the strategy that provides an acceptable risk at an affordable cost.

SARA Title III explicitly provided for public access to EHS data and vulnerability assessments, but did not explicitly require LEPCs to engage in active dialogue with the community at these stages. However, the law did envision public participation once a local emergency operations plan had been devised and implicitly presumed that a risk dialogue would mobilize community support for the implementation of the selected hazard management strategy.

SARA Title III arose from a recognition of communities' limited capacity to assess their vulnerability to chemical hazards and to select and implement an effective hazard management strategy [106]. Previously, there was limited guidance available from federal $[24,100]$ and state (e.g. [64]) agencies, but SARA Title III directed the National Response Team (a group of federal agencies headed by the Environmental Protection Agency and the Coast Guard) to prepare and disseminate extensive guidance on chemical hazard management.

Although SARA Title III's goals were widely accepted, many critics expressed doubts that this legislation would achieve its aims and some supporters expected it to achieve more than the law required. Now that more than a decade has passed since SARA Title III was enacted, it is possible to review its effectiveness. To accomplish this assessment, we will examine the history and context of the law, review the positive and negative predictions of its success, and summarize the results of empirical studies examining the positive and negative consequences of its implementation. We pay particular attention to studies of LEPC effectiveness, which represent the most direct impact of this legislation on community emergency planning. We close with an overall appraisal of the law's effectiveness and suggestions for improving its implementation. 


\section{SARA Title III's historical context}

SARA Title III attempted to enhance the effectiveness of communities' chemical hazard management by involving a wide range of stakeholders in the process [29]. These stakeholders included local, state, and federal government agencies; the general public; and EHS handlers. At the local level, few of SARA Title III's provisions were altogether new. Bierlein [5] described six different pieces of federal legislation - SARA Title III, Hazardous Materials Transportation Act, Clean Water Act, Resource Conservation and Recovery Act, Toxic Substances Control Act, and Occupational Safety and Health Act — that had instituted requirements for toxic chemical safety. Moreover, some communities and states already had established Right-to-Know legislation requiring hazardous materials handlers to inform workers and the public about chemicals being produced, used, or stored onsite [92]. Also, some communities had established disaster planning councils to coordinate the development of local emergency preparedness [21,22,32,33], and many fire departments had established routine contacts with local industry to support their fire pre-incident planning efforts [43]. However, none of these activities was widely adopted across the United States at the time that SARA Title III was passed.

SARA Title III represented a significant departure from other federal programs for emergency preparedness. The most prominent federal programs in the early 1980s were those for nuclear attack (extended under FEMA's Integrated Emergency Management System to include natural hazards) and for commercial nuclear power plants (expanded significantly after the accident at Three Mile Island). SARA Title III differed from these efforts in its degree of regulatory decentralization. In SARA Title III, the federal government established a regulatory requirement for community vulnerability assessment without involving itself directly in the process. This is in marked contrast to the role of federal agencies in the assessment of hazards from nuclear attack and commercial nuclear power plants. For both of these threats - and for natural hazards such as floods, hurricanes, earthquakes, and volcanoes - hazard assessment had been (and still is) conducted almost completely by federal agencies.

SARA Title III also established an innovative approach to the process of planning for emergency preparedness and hazard mitigation. Under the nuclear attack program (called Crisis Relocation Planning - CRP), planning was highly centralized. Federal plans designated evacuation communities, which in a crisis would relocate to host communities. The local role in CRP was to develop the details of plans to facilitate an evacuation or to receive evacuees [79]. Efforts at the local level also tended to be centralized, a process that could be characterized as consisting of an isolated Civil Defense Director who wrote paper plans that were seldom read and never tested [45]. This structure created problems in CRP program implementation [63]. The planning process for nuclear power plants was similarly narrow in the scope of local agency representation, although in that case local emergency operations plans (EOPs) often were developed by contractors to the nuclear utility rather than the local Civil Defense Director.

However, limited the nuclear attack program was in terms of its planning process, it did have the signal virtue of providing substantial funding for planning activities. Federal funding followed logically from the program's origins in federal responsibility for national defense. Similarly, those developing nuclear power plant EOPs also were funded substantially 
by outside sources - in this case, the nuclear utility whose operating license could be revoked if communities around the plant could not pass federally evaluated full-scale emergency exercises. This systematic program of corporate financing for community emergency preparedness was feasible because nuclear plants consist of only a few basic designs constructed on approximately 100 sites nationwide and are billion dollar facilities operated by large corporations.

In contrast to then-existing programs, SARA Title III did not provide local jurisdictions with federal vulnerability analyses or federal funding for emergency preparedness and hazard mitigation. These circumstances led many to deride SARA Title III as yet another "unfunded mandate" in which federal authorities recognized a problem and simply demanded that local governments solve it regardless of their level of vulnerability, capacity, or commitment. Unfortunately, the widespread distribution of toxic chemicals makes it infeasible for the federal government to rely on previously used methods of control. EHSs are found at thousands of facilities across the country that range from municipal swimming pools to massive petrochemical complexes, thus differing significantly in terms of the technological sophistication of their production processes and the size of their financial resources. There is similarly wide variation in the circumstances of local governments, who differ in their vulnerable populations' size and composition, their technical and financial resources, and their administrative structures. Under such conditions, a federal plan based on centralized planning and direct regulation of EHSs would be extremely expensive to administer and quite likely to fail anyway.

Under SARA Title III, federal agencies participated in vulnerability assessments only by providing technical guidance for computing a vulnerable zone (VZ) for each EHS facility (e.g. [101]). This contrasts with the establishment of a uniform 10-mile "emergency planning zone" for all commercial nuclear power plants [107]. Moreover, SARA Title III's emphasis on guidance rather than mandates was implemented by disseminating federal documents describing a planning process [73], criteria for plan evaluation [74], and guidance for conducting emergency exercises [75]. This process differs from nuclear power plant emergency preparedness, wherein federal authorities directly evaluate all aspects of communities' levels of emergency preparedness [108]. In sum, affected communities had considerable discretion in implementing SARA Title III. Local authorities could judge for themselves what level of expenditure for risk reduction was warranted by their degree of hazard vulnerability and community support for hazard management. The law does provide legal sanctions for a broad list of infractions such as a failure to submit an emergency plan, to report a release, or to comply with Right-to-Know requirements [105]. However, more immediate and powerful mechanisms of federal control, such as the loss of a grant for inadequate nuclear attack planning, or the loss of the operating license for inadequate planning in areas around a commercial nuclear power plant, were notably absent.

\section{Hopes and fears for SARA Title III}

Given the novelty of the hazard management process defined in SARA Title III, it should be no surprise that some stakeholders were convinced that the law would be a complete failure, while others just as confidently anticipated total success. According to Kartez [37,38], 
the limited explicit procedural requirements imposed by SARA Title III led to a wide range of unwritten expectations that differed among stakeholders.

\subsection{Critical arguments}

One of the principal opposing arguments arose from the EHS threat's complexity. Some observers contended that data on chemical quantities, properties, and effects in reporting forms was so technical as to be almost incomprehensible to most municipal officials and completely unintelligible to the average citizen [38]. Shabekoff [91] reported that others dismissed the legislation as nothing more than "an exercise in public relations" producing an illusion of understanding chemical threats without a substantial understanding of how to manage them.

Another major argument against SARA Title III was that it had failed to provide communities with a "Right-to-Act", forcing even those communities that did understand the danger of chemical hazards to submit to industry's superior economic power [70]. Moreover, SARA Title III's policy of local choice raised questions about environmental equity because poor and politically powerless communities might adopt lax safety standards to retain existing facilities and to attract new ones [23]. This argument is consistent with the position that delegation of responsibility is inappropriate when political conflicts over values are disguised as purely bureaucratic choices among alternative technical solutions [61]. Such delegation also is problematic when responsibility is assigned to a lower and weaker level of government that lacks the knowledge or power to resolve a conflict between the interests of private industry and those of the public at-large. Historically, the federal government has retained oversight responsibility when the specialized technical resources and the financial assets of private corporations exceed those of local government. The judgment that only the federal government could regulate technological hazards was widely accepted in the case of the nuclear power industry and SARA Title III critics found this argument to be equally applicable to EHS handlers.

Finally, SARA Title III received a mixed response from the chemical industry, which already had initiated its Community Awareness and Emergency Response Program in 1985 [8]. One the one hand, EHS handlers were relieved to deal with only one set of requirements imposed by the federal government rather than multiple, potentially conflicting, state regulations. On the other hand, many plant personnel were concerned about working with community agencies other than the fire departments with which they were familiar. They were especially apprehensive about meeting with the public, whom they expected to be angry and irrational.

\subsection{Supportive arguments}

Other stakeholders optimistically believed that SARA Title III disclosures would improve the quality of risk communication $[7,26]$, promote a reasoned dialogue about tradeoffs involved in community hazard management $[30,90]$, and empower local governments, emergency managers and the public to demand increased safety from industry [29,71]. Of course, these arguments depend critically on the assumption that EHS facilities would participate in these discussions - a belief that rested upon theoretical perspectives such 
as "self-regulation" [78] and "adaptive policies" [4]. These arguments assert that facility managers would recognize cooperation as being in their long-term best interest - even if this was nothing more than as a hedge against adverse public reaction to dangers revealed in the hazard data. Moreover, companies failing to take such initiatives would face public pressure from community safety advocates who could use the LEPC as a forum for promoting reduction in toxic chemical hazards. In particular, communities might use the LEPC as a vehicle for demanding that EHS facilities provide technical and financial support for improvements in local emergency preparedness, that new facilities be subject to zoning or site/design restrictions, or even that industry engage in chemical source mitigation by substituting less hazardous chemicals, reducing inventories, or eliminating hazardous processes altogether [50].

Other observers contended that SARA Title III would yield enhanced effectiveness in local emergency planning arising from multi-jurisdictional, public/private cooperation in "community partnership" [76]. Morehouse's [70] concern about the overwhelming power of local industry was countered by Schwab [90], who advocated an "environmental federalism" that would allow pollution standards (and, by extension, all other hazard management standards) to vary from state to state based on the costs and benefits involved.

\subsection{Key issues identified by the controversy}

The disparate expectations about SARA Title III's effectiveness can be attributed to differences of opinion about implicit assumptions contained in the law. Significantly, proponents and opponents did not disagree about the level of local capacity - both sides agreed it was lacking. Specifically, for an LEPC to convert EHS data into assessments of community vulnerability, it needs not only the identity and quantity of the EHSs (which are supplied by the handler), but also their physical state, volatility, and toxicity. In addition, the LEPC must provide data about the nature of the terrain and make assumptions about meteorological conditions at the time of the release [67]. Finally, VZs must be calculated either by hand [101] or using a computer program such as CAMEO [77] or ARCHIE [25]. Moreover, LEPCs also must use this assessment of VZs to formulate hazard management strategies. As noted earlier, emergency preparedness and onsite and offsite hazard mitigation are elements of such a strategy, but emergency preparedness is the only one of these that is a familiar task for local jurisdictions. Offsite hazard mitigation (e.g. land use regulation) is performed by local agencies that rarely are rarely involved with emergency response agencies, and onsite chemical hazard mitigation is a topic on which few if any local agencies have expertise. Thus, chemical vulnerability analysis and chemical hazard management strategy formulation are both complex and unfamiliar demands on local government capacity.

If local capacity were lacking, as all agreed, the question was whether it could be improved and, if so, how the improvements would be achieved. As Fig. 2 shows, local capacity can be bolstered by state and federal agencies or supplemented by local industry. It is at this point that proponents and opponents diverge. At the time SARA Title III was enacted, there was only modest support from state and federal government. Few state agencies provided guidance specifically for hazardous materials and, even then, this consisted mostly of "fill-in-the-blank" plans [64]. Support from federal agencies was somewhat more detailed, 


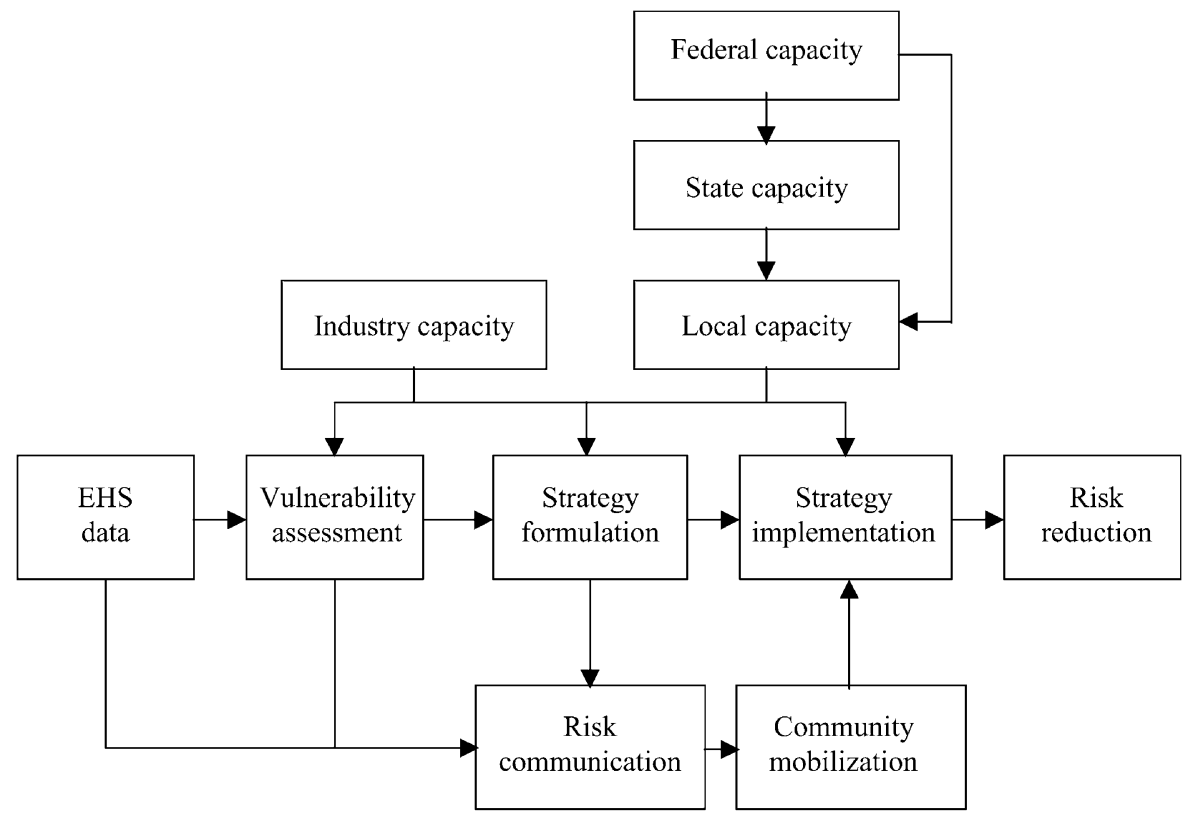

Fig. 2. A revised model of community toxic chemical hazard management.

but had been established only recently [24,100]. The prevailing lack of state and federal support suggested that assistance would not be forthcoming from these sources but, on the other hand, SARA Title III's commitment to capacity-building by the National Response Team was grounds for optimism. The net effect was a degree of ambiguity that could be interpreted either positively or negatively.

The likelihood of support from local EHS handlers would depend upon a community's relationship with industry. If the relationship were cooperative, as SARA Title III supporters maintained, then an LEPC would be able to obtain assistance from industry as well as from federal and state agencies. However, if a community's relationship with industry were antagonistic, as the critics assumed, then an LEPC could succeed only if it could mobilize local commitment to establish toxic chemical hazard management as a community priority.

Unfortunately, environmental hazard management has been documented repeatedly to be a low priority for local government $[20,49,68]$ because it conflicts with local bureaucratic and political processes [89]. This conflict arises because it is relatively improbable that an incident will occur in any given year or, more directly to the point, during the tenure in office of those local officials who must allocate resources $[6,88]$. Consequently, resources usually are assigned to immediately pressing jurisdictional demands such as routine police patrols, parks, and social services [42,62,97,111]. Notwithstanding this general pattern of public indifference to environmental hazards, there have been events such as Love Canal that have galvanized public reaction, which then elicited a governmental response. Thus, 
the prospects for locally generated resources also were ambiguous enough to be interpreted either pessimistically or optimistically.

In summary, observers' unwritten expectations about SARA Title III hinged on four important questions. The first of these was whether technical guidance would be forthcoming from federal and state agencies. The second question was whether technical support would be provided by the EHS facilities themselves. For this to be the case, there would need to be a cooperative relationship between them and their communities. The last two questions arise from the public's alternation between grave concern and utter indifference to environmental hazards. Thus, the third question is whether LEPCs would be able to analyze their communities' hazard vulnerability so that they would have a rational basis for chemical hazard management. Finally, the fourth question is whether LEPCs would engage in a systematic program of risk communication because this would be necessary to ensure that space would be created on the public agenda $[6,83]$ for a reasoned dialogue about chemical hazard management options.

\section{SARA Title III's outcomes}

In the past decade, empirical evidence has accumulated to support an assessment of SARA Title III's effectiveness. Unfortunately, the data are limited; there is no single comprehensive set of data on this law's outcomes across all states. However, it is rare that an evaluation of any public policy would be able to draw upon a single comprehensive data source [96]. Thus, we must follow the general model of meta-analysis [35] by marshalling evidence from studies that address different policy components, and that were conducted at different times by different researchers.

\subsection{Principal large-scope studies}

One series of reports documenting the effectiveness of SARA Title III implementation focused on compliance with specific provisions of the law. National Governors' Association (NGA) staff repeatedly surveyed all 56 SERCs on the status of SARA Title III regarding state legislation and agency roles, LEPC organization, activities, and methods of funding (e.g. $[28,72,94,95])$. Similarly, Rest [85] was concerned with the responsiveness of communities to SARA Title III's goals and LEPC implementation. Although this study reported the results of observations, interviews, and records reviews from three different states, the data came from only four LEPCs. Baram et al. [3] studied corporate response to SARA Title III, looking at facilities' compliance with disclosure requirements, involvement in emergency response planning and LEPCs, and efforts to communicate risks directly to the public. These researchers presented case studies of eight large EHS handlers in a wide range of manufacturing industries in different areas of the country. They accessed a variety of documents, including company and public records, and interviewed a wide range of stakeholders such as company management, LEPC members, community officials, news media representatives, and environmentalists.

Three national surveys of LEPCs have been conducted. Kartez [38] describes the results of two different data collection efforts, the first of which was conducted in 1989. Municipalities 
with populations of $>20,000$ that had participated in a 1988 International City Management Association study of emergency planning practices were asked to report on 165 LEPCs. A second survey, executed in mid-1992, obtained new information from 140 of the LEPCs included in the 1989 study plus 123 additional LEPCs derived from a 5\% probability sample of the 4008 LEPCs nationwide.

Reports by Rich et al. [18,86,87] described data collected from LEPCs in 1989 but, unlike the Kartez surveys, they were not based on probability sampling. Instead, an attempt was made to obtain a sample that was representative of (not randomly selected from) the 10 Environmental Protection Agency regions and differing levels of LEPC activity, with a balance between rural and urban areas. These authors selected ten states - Alabama, California, Louisiana, Maryland, Missouri, New York, Rhode Island, Utah, Washington and Wisconsin - and mailed questionnaires to the chairs of all 388 functioning LEPCs, realizing a $56 \%$ completion rate.

Adams et al.'s [1] survey provided considerable statistical precision regarding LEPC status throughout the country. Their sampling procedure, which produced 1155 responses, was population-weighted to avoid under-representing LEPCs from states (California, Minnesota, and Oregon) having a few large emergency planning districts (EPDs) and overrepresenting LEPCs from the states (Massachusetts, New Hampshire, and New Jersey) with many small EPDs.

Finally, Lindell and his colleagues [45-48,52-59,110] conducted a series of eight surveys on LEPCs located in the Midwest. Lindell and Meier [48] surveyed the Chairs of all 97 LEPCs in Michigan in 1990, focusing upon LEPC composition, activities, and emergency planning outcomes. Lindell and Whitney [52] conducted a similar survey the following year, examining LEPC organizational environments, internal structure and team climates. Lindell [45] extended this work by preparing a preliminary assessment of LEPC effectiveness, and Whitney and Lindell [110] examined the role perceptions, member commitment, and performance of 204 members of 57 Michigan LEPCs. Lindell et al. [56-58] extended this knowledge base in 1994 by studying Chairs and members of 180 LEPCs in Illinois, Indiana, and Michigan. These data have been further analyzed to identify correlates of organizational effectiveness [55] and examine the job demands of the Information Coordinator role in 83 of those LEPCs [53]. Other studies assessed the influence of organizational climate on LEPC effectiveness among 1196 LEPC members in those three states [47] and compared the results of standardized questionnaires with open-ended interviews with 21 members of a Michigan LEPC [54]. Collectively, these studies have examined the effects of LEPCs' physical and social environment, their organizational structure and processes, and the characteristics of LEPC officers and members on outcomes at the individual (effort, attendance, turnover intentions, job satisfaction) and organizational (LEPC Chair and SERC staff ratings of performance, submittal of emergency plans for SERC review).

\subsection{Outcomes for explicit requirements of SARA Title III}

SARA Title III explicitly mandated that industry disclose the presence of EHSs, that SERCs and LEPCs be created, that LEPCs achieve diverse representation, that LEPCs prepare and submit emergency response plans, and that LEPCs engage the public. The available data regarding each of these five mandates is reviewed below. 


\subsubsection{Industry hazard data disclosure}

It appears that the goal of industry disclosure has been largely achieved. Miner [69] cited simplification of the reporting process in Wisconsin for high compliance levels in that state's pulp and paper industry, although specific counts of compliant firms were not reported. Similarly, reviews of chemical accident reporting in the European Community [82] and implementation of hazardous substance regulations in Australia, Germany, the United Kingdom and the United States [60] reported high levels of industry compliance in the US. The Baram et al. [3] study of eight firms reported complete voluntary compliance, although the firms all were very large companies. Fillo and Keyworth [27] contended that the growing availability of computer software for reporting has produced high levels of industry disclosure.

LEPCs' reports of data received from EHS handlers also tend to substantiate claims of high compliance levels. Lindell et al. [56-58] found that LEPCs in Illinois reported receiving data from an average of 91 facilities (ranging from 0 reports to 550), while Indiana LEPCs received an average 42 facility reports (ranging from 0 to 285), and Michigan LEPCs averaged 23 facilities each (ranging from 0 to 138). LEPC Chairs in these states generally expressed strong, but not complete satisfaction with the quality of their LEPCs' efforts in collecting and filing hazard data received from industry. Moreover, data from a national sample indicate that identifying non-reporting firms is a high priority for LEPCs, with $29 \%$ of all LEPC chairs nominating this activity as an area that requires significant improvement [1]. Discussions with SERCs and LEPCs suggests that reporting is high in the petrochemical industry (SICs 28 and 29), as well as in other manufacturing sectors (SICs 20-27 and 30-39), but tends to be more problematic in sectors where EHS handlers are not aware of SARA Title III and its reporting requirements because chemical use is incidental to their operations (e.g. farm use exceeding threshold planning quantities of ammonia).

\subsubsection{Creation of SERCs and LEPCS}

The requirement to create state and local emergency planning organizations has been quite successful; all states have formed SERCs and designated LEPCs [28,31]. Thirty-one states have established counties as the basis for LEPCs, but other administrative units also have been used as EPDs. One state has a single statewide LEPC, while four states have regional LEPCs ranging from 6 to 11 in number. At the other extreme, four states in the Northeast have township LEPCs, with the number of LEPCs per state ranging from 156 to 558. The substantial variation in the administrative level for LEPCs shows there is no clear consensus on an optimal geographical scope of responsibility and, therefore, the number of LEPCs to be overseen by a SERC. Moreover, as will be discussed below, the fact that LEPCs are established does not mean that they are functioning. Some SERCs have been forced to name county commissioners as LEPC members because no nominations were forthcoming from the designated EPDs.

\subsubsection{Diversity in LEPC membership}

SARA Title III explicitly required LEPC membership to include 13 different constituencies or groups including citizens groups, health and social service organizations, public safety agencies, private industry, and state and local officials. With few exceptions, available data suggest that LEPCs have achieved diversity in representation. One national survey 
[1] reported that 12 of 13 types of organizations were represented on more than $50 \%$ of all LEPCs (only state officials were significantly under-represented). Another national survey $[86,87]$ found LEPCs to have diverse memberships, but also reported that LEPC members believed they had inadequate representation from the media and the public. An early study [48] documented an average of about 11 agency types (from a possible list of 20) represented on Michigan LEPCs, a result subsequently replicated [52]. Further research [56-58] showed that most (69-82\%) of the LEPCs in Illinois, Indiana, and Michigan included local industry members, and sometimes even involved truck and rail carriers. These data also document that representation tends to draw more heavily from public safety agencies (fire service, law enforcement, and emergency services) than from other agencies of local government. This is consistent with research on LEPCs in Texas, New Jersey and Massachusetts, which found that citizens groups and citizens in general were less involved in the organizations studied [85]. The latter data are particularly significant because the communities in that sample were selected for having experienced a recent chemical accident - a circumstance that would, at least in the short run, be expected to activate the public.

Similarly, Kartez [38] found that only $49 \%$ of LEPCs had any community group representation and, of those, $70 \%$ had representation from only one of the three focal types of community group - environmental, neighborhood, or labor. Only 4\% of LEPCs had representation from all three groups. Finally, Baram et al. [3], reported that while the LEPC was an effective bridge between industry and emergency management officials in the states they studied (Texas, New Jersey and Massachusetts), but citizens were not only absent from the LEPC, but they were uninterested in participating. Significantly, the regulatory requirement for diverse representation on LEPCs is supported by findings from one study [85] reporting that these organizations tend to focus on emergency response plans more than accident prevention (mitigation) or risk communication when industry is strongly represented on LEPCs. By contrast, higher proportions of citizen membership yield concern with a broader range of issues.

\subsubsection{LEPC development of community emergency response plans}

LEPC compliance with the requirement to prepare and submit EOPs for SERC review varies across states, but appears to be increasing. Statistics compiled by the National Governors Association indicate that in 1990 only 19 SERCs reported that all their LEPCs had submitted plans. Another 17 states reported only some submissions, and 20 provided no information [94]. SERCs in the latter category probably have few LEPCs in compliance. By 1993, 22 states or territories reported that all their LEPCs had submitted plans to the SERC, and another 16 states or territories reported that at least some LEPCs had submitted plans. Only 18 of the 56 states or territories provided no information about LEPCs' submission of emergency plans. This is a significant improvement over earlier results.

One must avoid assuming that LEPCs' submission of EOPs to their SERCs means that they have achieved a significant level of emergency preparedness. While the preparation and submission of an EOP — assuming an appropriate planning process - can reflect preparedness, the correlation is less than perfect [49]. Interviews from one state in the Midwest reporting full compliance with the EOP requirement revealed that its LEPCs had submitted generic plans prepared by an outside consultant rather than community-developed plans with site-specific data [59]. This finding raises concern that other LEPCs also are 
submitting "paper plans" produced to satisfy regulatory requirements rather than viable EOPs [45]. Although no systematic assessment of the quality of LEPCs' EOPs has been undertaken, Kartez's [38] finding that $46 \%$ of LEPCs had updated their emergency response plans annually, while another 37\% updated at least once between 1988 and 1992 suggests that many LEPC are taking the planning process seriously.

\subsubsection{Public access to hazard data}

Given the low levels at which community groups are represented on LEPCs, it should be no surprise that public access to hazard data is poor. Indeed, available data show an apparent conflict between LEPC member perceptions and their information dissemination actions. A probability sample of 1032 LEPC members in Texas [98] found that $43 \%$ believed the LEPC's two most important tasks were to interpret MSDSs and provide risk information to the public. Furthermore, $47 \%$ believed that, if asked, their LEPC would initiate a risk communication program. In a national sample, $92 \%$ of the LEPCs reported having a designated office to disseminate information [86]. However, only 59\% of those who had established an office advertised its address or phone number, while only $25 \%$ of the LEPCs invited the public to meetings, and only $6 \%$ actively disseminated information. This same study found that relatively few LEPC members rated their communication with the public as excellent - 11\% of members from emergency response organizations, $7 \%$ from business, $11 \%$ from government, $10 \%$ from watchdog groups, and $14 \%$ of independents. The eight chemical companies studied by Baram et al. [3] had undertaken voluntary public outreach information campaigns, but found that public response to these campaigns was minimal.

\subsubsection{Overall compliance with SARA Title III provisions}

Adams et al. [1] examined national data on LEPC compliance with the law's requirements for staffing (having an LEPC Chair, an Emergency Coordinator, an Information Coordinator, and representation from at least 12 of 13 designated groups), organizational activity (formal meetings), planning outcomes (developing an emergency response plan incorporating key planning elements, submitting this plan to the SERC, and reviewing it annually), and public outreach (advertising meetings and publishing notice of the availability of hazard data and the emergency plan). Their data reveal that $21 \%$ of the LEPCs could be classified as noncompliant because they met fewer than 6 of the 10 central provisions of the law. On the other hand, 35\% of all LEPCs could be classified as mostly compliant (meeting 6-8 provisions), while $44 \%$ were fully compliant (meeting 9 or 10 provisions). In general, these data suggest that the majority of LEPCs across the country meet the major provisions of SARA Title III, but a significant number are totally ineffective.

While these data call attention to LEPCs' failings, it also is important to note that many LEPCs have exceeded the law's minimum requirements. One national sample reported that $37 \%$ of the LEPCs had developed site plans for all or most facilities, and another $36 \%$ had developed at least some site plans [38]. Another study found that $61 \%$ of LEPCs had taken three or more proactive steps not explicitly required by the law [1]. These included meeting quarterly or more frequently, addressing natural hazards in the plan, exercising their plan in the previous year, updating the plan in the previous year, and using EHS data to recommend hazard mitigation measures to local government or industry. 
Available empirical evidence suggests that most LEPC members consider their organizations to be effective $[85,86,87,98]$. These self-assessments appear to have a significant degree of validity because Chairs' assessments of their own LEPCs' effectiveness are significantly correlated with SERC staff assessments of those LEPCs [47]. In addition, LEPC Chairs do give their organizations high ratings on some tasks, but low ratings on others. For example, LEPC Chairs in Illinois, Indiana, and Michigan [56-58] gave relatively high ratings to the quality of their performance in organizing and administering the LEPC and in collecting and filing hazard data, but also gave themselves low ratings on their preparedness for elements of protective response actions (e.g. analyzing evacuation time estimates or assessing the effectiveness of sheltering in-place) that independent evidence indicates are not being done.

Some attention has been given to the possibility that contextual variables such as community characteristics influence LEPC effectiveness. To date, there have been inconclusive results on the impact of jurisdictional size, wealth, growth rate, employment, minority concentration, and industry concentration. Adams et al. [1] reported that compliance was significantly correlated with jurisdiction size, median household income, and percent of urban population, while Kartez [38] found only weak or inconsistent effects of these variables. The conflict between the two studies may arise from the fact that Adams et al. [1] found the strongest effects in the smallest, poorest, and most rural jurisdictions, which were under-represented in the 1992 Kartez sample and altogether absent from his 1989 sample. In a regional sample, LEPC effectiveness had small but statistically significant correlations with hazard vulnerability (the number of EHS facilities), recent disaster experience, and community resources $[47,55]$. That same study also found somewhat larger correlations for media coverage and elected official support, but all external contextual variables had smaller correlations than variables assessing internal structure (paid staff, subcommittees, and broad representation) and process (formalization of member orientation, meeting formalization, and goal setting). This is finding important because internal structure and process variable are under the control of the LEPC.

LEPC leaders and members agree that their organizations could be more effective with higher levels of stable funding [56-58,85,87], but many LEPCs function beyond minimal requirements at current funding levels and many jurisdictions have developed their own sources of financial support. Fourteen states provide allocations through performance-based, formula-based, or matching grants [28]. A significant proportion (34\%) of all LEPCs have an operating budget, $28 \%$ receive funds from local government, and $12 \%$ receive funds from local industry [1]. Fees imposed on EHS facilities were reported by $20 \%$ of the LEPCs in Kartez's 1989 survey and 26\% in his 1992 survey [38]. The Adams and Kartez data sets appear to conflict, but Kartez's respondents might have been reporting both direct funding from industry to the LEPC and indirect funding via the state, while the Adams data include only funding from industry.

\subsection{Outcomes for unwritten expectations associated with SARA Title III}

As noted earlier, the comments by SARA Title III critics and supporters articulate four sets of issues regarding SARA Title III implementation. The first issue is about technical support by state and federal agencies, while the second concerns the relationship between 
EHS handlers and their communities as manifested by EHS data disclosure and the provision of technical assistance to the LEPC. The third issue is the extent to which LEPCs have been successful in using EHS data to assess community vulnerability, while the fourth deals with LEPCs' use of risk communication programs to mobilize community support for toxic chemical hazard management.

\subsubsection{Federal and state technical guidance}

The past decade has seen a major increase in the amount of federal and state technical guidance for hazardous materials emergency planning. In the years after SARA Title III's enactment, federal agencies issued documents on hazard analysis [25,101], planning processes [73], criteria for evaluating local plans [74], risk communication [102], and implementation "success stories" [103]. Indeed, there were enough planning documents for EPA to publish a bibliography of these materials as a separate document [104]. There also have been some contributions from states such as Michigan, which published guidance on the operation of LEPCs [66] and protective action recommendations in toxic chemical emergencies [65].

\subsubsection{Assessments of community vulnerability}

The available evidence suggests that disclosing EHS data has had outcomes that do not fit the predictions of either the pessimists or the optimists. The pessimists were correct in contending that the reporting forms contain data that is narrow and technical, to the point that LEPCs themselves still are struggling in their efforts to convert EHS data into vulnerability assessments [27]. Kartez [38] reported that 43\% of the LEPCs had computed VZs for all or most hazardous facilities, while another $29 \%$ had estimated vulnerability for at least some facilities. Lindell's 1997 followup survey of LEPC Chairs in Illinois, Indiana, and Michigan indicates that $16 \%$ of the LEPCs had used hazard data to calculate VZs using the EPA Technical Guidance for Hazards Analysis [101], 36\% had analyzed VZs using computer models, 23\% had determined VZs using the DOT Emergency Response Guidebook [99], and $10 \%$ had calculated VZs using other methods. In all, 59\% of the LEPCs had calculated at least some VZs. These data indicate that many LEPCs are capable of using hazard data for their intended purposes, but nearly half have done no VZ calculations and nearly a quarter of them have used the DOT Emergency Response Guidebook [99] to calculate VZs for fixed-site facilities.

\subsubsection{Relationships between EHS handlers and their communities}

The expectation that conflict would arise between EHS handlers and their communities generally has not been borne out. Quite the contrary, there have been national efforts by industry associations and individual efforts by private firms to provide information, funding, and other forms of support to LEPCs, to local and state officials, and to the public [3]. Similarly, Chess et al. [15] described one chemical firm's major investment in promoting local chemical hazard awareness. Indeed, the Chemical Manufacturers Association had an active program of emergency planning support to communities that was instituted before the passage of SARA Title III [8]. CMA has continued this activity and generated new materials aimed at supporting its members and their communities [14]. This support also has taken the form of Chemical Manufacturers Association guidance on process safety management 
[9], community emergency planning [8] and exercises [11], site emergency planning [10], emergency warning systems [12], and risk communication [13].

Kartez [38] found that industry has provided substantial assistance to LEPCs in conducting hazard analysis (55\%), developing mutual aid agreements, $(55 \%)$, interpreting hazard data (48\%), developing data management systems (44\%), performing public outreach (34\%), and acquiring funds for hazmat training/operations (26\%) and computers $(22 \%)$. Lindell et al. [56-58] found that LEPCs often used Chemical Manufacturers Association training materials, although to a lesser degree than federal resources such as the EPA's Technical Guidance for Hazard Analysis [101] and computer software such as CAMEO and ARCHIE [19,36,67]. Smith [93] reported that EHS handlers in the pulp and paper industry approached SARA Title III requirements as opportunities to build trust in their communities. Some might describe industry involvement with LEPCs as co-optation rather than sincere participation, but even the former would be an improvement over the state of affairs in most jurisdictions before SARA Title III [17].

There is little support for the contention that Title III failed to provide communities with a "Right-to-Act", forcing even those communities that did understand the danger of chemical hazards to submit to industry's economic power. If anything, the data support the opposite conclusion. Even in the absence of significant community pressure (or in most cases, in spite of a substantial lack of community interest), EHS facilities have engaged in hazard mitigation actions utilizing a variety of strategies [41]. Early anecdotal reports indicated that some companies did not even know all of the hazardous materials they had onsite at the time SARA Title III went into effect. Once these firms were legally required to report EHS inventories, they took actions to avoid being labeled as EHS handlers. As has been documented elsewhere [51], these hazard mitigation activities included disposing of rarely used chemicals, reducing inventories below threshold planning quantities for chemicals that they could not eliminate, and substituting alternative chemicals or alternative production processes where possible. The anecdotal reports are consistent with survey data showing that $41 \%$ of all LEPCs had made hazard reduction or prevention recommendations to industry or local government [1].] Ten percent of the LEPCs in Kartez's [38] 1989 survey claimed that some EHS handlers in their jurisdictions had engaged in chemical source reduction or substitution actions, while even more reported establishing transportation route (14\%), site/design (18\%) or zoning (21\%) requirements for EHS facilities.

\subsubsection{Community outreach}

There is relatively little support for the claim that SARA Title III would promote public dialogue; LEPCs have had minimal contacts with their communities. Most LEPCs (88\%) have made hazard data and EOPs available to the public, but less than half of them have published newspaper notices to inform the public of this fact. Even among functioning LEPCs (those complying with a majority of SARA Title III's ten legal requirements), nearly a third failed to advertise their meetings to the public [1]. This finding is consistent with data indicating that LEPCs' outreach activities tended to be limited in scope [38]. Most LEPCs (79\%) make EHS data publicly available for residents to copy, but only $37 \%$ publicize their activities in local news media, 33\% place a copy of the emergency plan in local libraries, and 38\% send speakers to community groups [38]. Other studies of LEPCs [56-58,85,98] have revealed similar patterns of low outreach activity. Baram et al. [3], 
while also reporting both citizen disinterest and LEPC inactivity in dissemination, found that citizens - without LEPC or industry help - were unable to understand EHS hazards or to interpret the significance of chemical volatility.

Furthermore, the data do not indicate that EHS data disclosure has motivated citizens to become either curious or furious about chemical hazards. Many LEPCs $(41 \%)$ receive no public inquiries during the course of a year and only $25 \%$ have received more than six in that time [1]. Michigan LEPCs received limited newsmedia coverage (typically 1-2 times per year) and an average of just under four information requests per year [48]. Similarly, Rich et al. [86], Rest [85] and Sutton [98] reported that the LEPCs experienced both low levels of media coverage and very low levels of citizen inquiry. However, some data indicate that public information seeking varies widely among LEPCs. Lindell et al. [56-58] found that the average number of public inquiries differed only slightly between states, but ranged widely between LEPCs in the same state (Illinois: mean $=2.2$, range $=0-20$ inquiries; Indiana: mean $=2.8$, range $=0-50$ inquiries; Michigan: mean $=1.7$, range $=0-27$ inquiries). Clearly, the sizes of these ranges indicate that citizen interest varies widely by community and is caused by factors other than LEPC dissemination efforts.

Overall, Rich et al. [87] reported that nearly two-thirds of LEPC members believed their organizations' attempts to secure citizen input were inadequate, and more than three-fourths felt their LEPC's public visibility was less than "good". Kartez [38] also found little evidence of public dialogue stimulated by LEPCs. Adams et al. [1] found that two-thirds of the inactive LEPCs blamed community indifference, more than one-third blamed lack of funding, and another third blamed lack of hazard vulnerability. Data from local and regional samples are consistent with these findings. Rest [85] found that LEPCs in three states under-represented citizens as members in general, tended to have activists as representatives who represented narrow citizen constituencies anyway, and rarely engaged in outreach. These same findings are echoed in the work of Baram et al. [3], Sutton [98], and Lindell et al. [56-58].

\section{Appraising SARA Title III and improving LEPCs}

The overall achievements of SARA Title III are less than some had hoped, but far greater than expected by others who feared the legislation would be totally ineffective. In fact, the levels of emergency preparedness and hazard mitigation stimulated by SARA Title III appear to be similar to those for natural hazards such as earthquakes, hurricanes, and floods [45]. LEPCs hold a central role in SARA Title III implementation and available research confirms that they generally have complied with the law's goals. Data showing $79 \%$ of LEPCs were mostly or fully compliant seven years after the SARA Title III deadline [1] substantially exceeds the rate of survival for voluntary community organizations, which is only about $50 \%$ per year [84].

However, research has documented substantial variation in LEPC performance between states, as well as between LEPCs within a state. This variation is important because continued improvement in chemical hazard management under SARA Title III depends on an enhanced level of LEPC performance. In the following section, we propose a number of suggestions for improving LEPC functioning that are derived from the research we have reviewed. The four principal areas of action are (1) federal and state guidance, (2) col- 
laboration between EHS handlers and their communities, (3) assessments of community vulnerability, and (4) community outreach.

\subsection{Federal and state guidance}

Federal and state government agencies have provided essential guidance to LEPCs in how to establish and test an emergency organization [73-75], but have addressed issues of routine administration only to a very limited extent (e.g. [66]). LEPCs almost certainly will continue to have limited resources, so they must make the best use of the resources already available to them by increasing their productivity. In the face of low levels of external funding, LEPCs must induce members to divert their attention from other professional activities or to contribute their own personal time. In either case, the amount of time devoted must be large enough to yield meaningful results, but not so large that members experience burnout. At least two studies conducted not long after SARA Title III was passed identified low levels of member time committed to LEPC activities as problematic [85,98], and the problem appears to have continued [107].

There are many methods of staffing and organization one can use to achieve higher levels of productivity without risking burnout. Specifically, LEPCs can become more effective when they add new members from diverse agencies to increase the range of knowledge, skills and abilities in the LEPC, when they hire paid staff, and when they form subcommittees $[3,48,52,54,85]$. Another factor whose presence is correlated with LEPC effectiveness is the availability of automated technology such as computer hardware and software for accessing databases and conducting vulnerability analyses [36]. Finally, an LEPC will be more effective when it provides members with specific descriptions of the organizational authority hierarchy, LEPC policies, their job duties, and work rules and procedures [34,55]. It will also be more effective when its members set annual goals for the LEPC and its subcommittees, assesses its performance annually, discusses this performance appraisal within the LEPC, and presents this performance appraisal to local appointed and elected officials. Finally, effectiveness also will be higher when an LEPC has meetings that are frequent, are scheduled on the same day of the week, time of day, and location, have an agenda circulated in advance, receive routine reports from subcommittees, and keep written minutes $[47,59]$. Such organizational activities not only have direct effects on LEPC effectiveness, but also have indirect effects by creating a positive team climate that increases individual effort and attendance and decreases turnover [47,52,110].

LEPCs also can improve their productivity by appropriately and aggressively using outside resources available to them. State sources, especially state government, are needed to provide specific guidance and individualized technical assistance. From a slightly different perspective, toxic chemical emergency planning can be conceptualized as an innovation that is diffusing across communities [80]. The significant impact on LEPC effectiveness of guidance from state-level agencies indicates that vertical diffusion processes are very important $[26,45,52]$. However, regional sources can promote lateral diffusion among LEPCs of "success stories" involving organizational structures and processes, hazard/vulnerability analyses, emergency plans and procedures, or mechanisms for public outreach [39]. In particular, there is a significant positive impact of membership in statewide LEPC associations, which means that relationships among peer organizations are important in enhancing 
LEPC effectiveness [53]. These observations are consistent with previous investigations indicating a need to avoid "top-down" approaches to emergency planning [20,63]. This is not to say federal efforts are unimportant; only that support from state agencies and networks of LEPCs representing multiple jurisdictions also make significant contributions to organizational effectiveness and should not be overlooked.

Team climate - members' interpretations of features, events and processes that take place in the work environment - also has been found to be important in enhancing LEPC productivity [47,52]. Team climate influences on the degree to which members' motivation is aroused, maintained, and directed toward group goals. Furthermore, team climate is important because it is related to LEPC members' job satisfaction and organizational commitment which, in turn, are related to members' participatory activities such as effort expended, attendance, and intentions to remain with the LEPC [110]. Important dimensions of team climate include the absence of role stress, (role ambiguity, conflict, and overload) and the presence of intrinsic or extrinsic rewards for emergency planning activities (job challenge, personal skill development, task significance, and public recognition). It also includes positive characteristics of LEPC leadership (the ability to structure team tasks, to communicate task assignments clearly, and to show consideration for team members), and the spirit of the workgroup itself (workgroup cooperation and team pride).

Another factor affecting LEPC productivity is the size of the EPD for which it is responsible. As noted earlier, states differ in the way EPDs are designated, ranging from township to statewide domains. The size of an EPD affects the work demands (and resource needs) of LEPCs, but decreasing the size of LEPCs to lower the work demands increases the number of LEPCs overseen by the SERC. Thus, optimizing the size of EPDs requires a balancing of three criteria: maintaining an adequate span of control for the SERC (which favors larger EPDs), obtaining efficient utilization of emergency planning and response resources (which also favors larger EPDs), and ensuring an LEPC's accountability to the communities in the EPD which favors smaller EPDs). Conflicts among these criteria imply that LEPC boundaries are unlikely to correspond to any single type of jurisdictional boundary within a state. In highly urbanized areas with many EHS facilities, it often is necessary to have multiple LEPCs within a single county. In rural areas where there are few EHS facilities, SERCs should consider consolidating counties within a regional LEPC. A high percentage of rural LEPCs may be inactive because local officials believe that an active LEPC requires a high level of resources that exceeds the relatively low level of vulnerability. Regional LEPCs could overcome this problem.

State and federal agencies also should extend their current guidance by providing much more information on techniques for accomplishing tasks that LEPCs currently are neglecting. Research to date indicates that LEPCs have made their greatest progress in assessing community vulnerability and developing EOPs, with much less accomplished in hazard mitigation, and very little involvement of citizens in community hazard awareness. As noted earlier, this state of affairs appears to be a function of LEPC membership composition. Lindell et al. [56-58], Baram et al. [3], Rich et al. [87] and Rest [85] all found that LEPCs are most heavily staffed by first-responder public safety agencies and, consistent with Kartez's [38] contention, have emphasized emergency preparedness over hazard mitigation. Moreover, within the domain of emergency preparedness, they have emphasized corrective (e.g. "patching and plugging") rather than protective (e.g. warning, shelter in-place, and evac- 
uation) actions by emergency responders. This emphasis is understandable in light of the tendency to define complex problems in terms of one's own area of specialization. Indeed, this finding extends to the realm of emergency preparedness in general, where experience indicates that during the impact phase of an accident or disaster, "each organization responds to its own private emergency" [49]. This tendency to define community hazard management very narrowly underscores the prevalence of communities' tendencies to assume that emergency planning is the exclusive province of fire and police departments. However, comprehensive chemical hazard management requires the special knowledge and involvement of a broad range of professionals [2].

Achieving greater diversity in the number and types of public agencies, private organizations, and citizens' groups represented on the LEPC is an important step, but developing a consensus on LEPC objectives also is needed. As Kartez and Lindell [40] have argued, effective emergency management requires development of a "shared schema" or common definition of disaster demands and emergency response tasks. Similarly, LEPCs must develop a consensus about the need for adding elements of hazard mitigation and community outreach to their current strategies emphasizing vulnerability assessment and emergency planning. Once LEPCs have established hazard mitigation and community outreach as agreed upon priorities, they must become cognizant of the techniques that can be used to achieve these objectives and also develop a consensus about the effectiveness, cost, and time, effort, knowledge and skill requirements of these techniques [49]. This redirection of LEPC commitment toward a broader range of hazard management alternatives will require a significant level of leadership by LEPC Chairs.

\subsection{Collaboration between EHS handlers and their communities}

Early pessimistic predictions about the success of SARA Title III appear to have overemphasized the conflict of interest between EHS handlers and their surrounding communities. The anticipation of conflict appears to have arisen from erroneous assumptions that EHS handlers are concerned only about short-term profit and that they operate so efficiently that any change in their operations will threaten this goal. The anticipation of conflict also seems to have presumed that communities are limited to two alternative courses of action - either the company must eliminate the dangerous chemicals or the community must continue to bear the risk [37,109]. In fact, this assumed dichotomy is false for a number of reasons. First, EHS handlers - like other organizations - tend to fall short of classical economic efficiency assumptions. For example, some of them are reported to have had many drums of unneeded chemicals onsite but it took a legal, not economic, stimulus to prod them to conduct a systematic inspection of their inventories. When some of these chemicals proved to be EHSs, they were eliminated.

Some critics of SARA Title III predicted that industry would use its economic power to avoid even inexpensive risk reduction measures [44]. In evaluating this argument, it is important to recognize that jurisdictions with large, diverse, and thriving economic bases can afford to confront any companies that do not reduce their chemical inventories. The loss of a single (even large) firm that relocated to avoid regulation would not be sufficiently threatening. More generally, when EHS handlers are unable or unwilling to take action, the community can take actions to increase safety without threatening the jobs and tax revenues 
derived from these companies. For example, zoning regulations can be used to specify the location of new chemical facilities and to define appropriate routes for transporting chemicals to new or existing sites. Moreover, communities can prohibit high-density land uses (e.g. hospitals, schools, and apartments) in areas adjacent to hazardous facilities [46,49]. Finally, communities can invest in emergency response resources such as emergency plans, fire fighting equipment, warning systems, and evacuation route improvements. These and many other risk reduction measures can be undertaken whether or not EHS facility managers cooperate with the community.

In summary, the data on SARA Title III implementation suggests that conflicts of interest between public safety and industry profitability may be more the exception than the rule because both parties have a commonality of interest in avoiding plant accidents (which not only are dangerous to the community, but also are expensive for the company). Moreover, there are many risk reduction options available in addition to chemical process changes. It is possible to promote chemical risk reduction by establishing an open dialogue between industry and local government and cooperation is likely. Nonetheless, industry has incentives to reduce risks on its own and communities can take unilateral actions to protect themselves through emergency preparedness and hazard mitigation even if industry cooperation is not forthcoming.

\subsection{Assessments of community vulnerability}

Federal agencies have provided excellent tools such as the Technical Guidance for Hazards Analysis [101], CAMEO [77], and ARCHIE [25] for assessing community hazard vulnerability. Moreover, they also provide the training needed to master these tools. However, many LEPCs are estimating VZs using the DOT Emergency Response Guidebook [99] or are not estimating VZs at all. Research should be conducted to determine specifically why the available tools are not being used, but it is likely that computer programs such as CAMEO and RCHIE are underutilized because many jurisdictions are unwilling to commit the staff time and expense required to become proficient in their use. The Technical Guidance for Hazards Analysis requires very little time to learn and use (in [46], the procedure was set up as a computer spreadsheet to assess vulnerability zones for 23 chemicals in just a few hours), but the manual appears formidable to many LEPC members.

One way to increase LEPCs' effectiveness in hazard vulnerability would be to develop a tool that requires no more than Web browser skills to operate. Such a website would make the intimidating calculations completely transparent to the user, who would need only to select a chemical, enter its quantity, and select the location type (urban or rural) and meteorological conditions. This procedure could be simplified even more if the website were constructed, so EHS handlers could enter their chemical data directly into the website, as well.

\subsection{Community outreach}

SARA Title III has not contributed to the development of a significant dialogue about toxic chemical hazard management with segments of the community other than the local government agency representatives who are LEPC members. This finding is consistent over 
time, across survey instruments, and between national and local samples. This is unfortunate not only because public involvement is an important provision of SARA Title III and, more generally, a basic principle of American government, but also because it impacts LEPC effectiveness as well. Research shows that community support is directly associated with higher levels of LEPC effectiveness [59] and also has an important indirect effect because it influences the extent to which LEPC funding becomes an issue on local and state political agendas $[6,83]$. Higher levels of community support — and subsequent local funding can be achieved by LEPCs that make citizens members of the LEPC, invite the public to LEPC meetings, actively seek media coverage, give talks to community groups, and share the process of developing community emergency response plans. Such outreach activities, together with credible vulnerability analyses, can form the basis for systematic upward influence to overcome local elected officials' perceptions of low hazard vulnerability, high cost of preparedness, and lack of capacity to implement mitigation policies [59].

\section{Closing observations}

The research on SARA Title III implementation provides substantial support for the contention that a federal environmental regulation with negligible funding can yield significant positive impacts on community hazard management. The EHS data disclosure requirements of SARA Title III have led to notable activity in vulnerability assessment and emergency preparedness and, to a lesser degree, hazard mitigation. Interestingly, much of this has been accomplished in the absence of significant pressures from community interest groups; some would even say in the face of high levels of citizen apathy [3]. This suggests that the more exacting requirements of the Clean Air Act Amendments Section 112(r) will be found to yield even greater risk reduction, albeit at greater cost to industry [16]. Research examining the implementation California's Risk Management and Prevention Plans (RMPPs) has produced similar conclusions [51]. The expense of the RMPP process - which requires EHS handlers to develop a safety assessment of the facility, an analysis of the offsite consequences that would result from an accidental release, and a hazard mitigation plan - has induced about half of the EHS handlers to take actions that remove them from the regulatory requirements. If these results for Southern California approximate the experience in the United States as a whole, toxic chemical regulation will be successful in substantially reducing unnecessary chemical risks to communities. This is particularly likely to be the case where the use of an EHS does not provide commensurate benefit to the chemical handlers, prompting them to decrease their chemical inventory below the threshold planning quantity or by substituting less hazardous chemicals.

The key role of the LEPCs in SARA Title III demands that researchers continue to study the organizational arrangements through which they operate, and that the results of such research be disseminated to LEPC and SERC Chairs. The discovery of the significant mediating effect of LEPC team climate designates an important basis and direction for such research. Specifically, it appears that addressing group processes within an LEPC is as important to its effectiveness as conducting hazard and vulnerability analyses, capability assessments [81], transportation analyses and the like. Research on LEPC climate quality and consensus indicate that both are significantly related to organizational outcomes [47], 
yet LEPCs are currently left to their own devices with regard to internal management and specifically the development of effective group processes. The provision of guidance in this area, and its adoption by LEPCs, is likely to enhance the effectiveness (and consequently, the task accomplishments) of these organizations.

SARA Title III has produced increased contact among public safety organizations, as well as promoting these agencies' contacts with other departments of government and with local industry. Whether this contact has resulted in a high degree of coordination and consensus about chemical hazard management has not been empirically determined, but at least the basis for these outcomes has been established. Since years of research on disaster management demonstrate that prior contact and communication among organizations is an important precondition for effective emergency response [49], it is likely that SARA Title III implementation has moved chemical hazard management forward in many communities. Furthermore, the creation of LEPCs has produced a structure that not only has great potential in chemical hazard management, but can be used as a model for managing other environmental hazards, as well. LEPCs represent a type of strategic planning process that — like the strategic planning required for such other community activities as transportation, economic development, and social service delivery - must address complex long-range issues possessed of low immediate priority for elected officials. The innovation is that LEPCs offer a structure for hazard management that can produce significant achievements in spite of the low priority assigned to planning activities by both political officials and citizens.

\section{Acknowledgements}

This work was supported in part by the National Science Foundation under grants BCS-9222600 and BCS-9796297. None of the conclusions expressed here necessarily reflect views other than those of the authors.

\section{References}

[1] W.C. Adams, S.D. Burns, P.G. Handwerk, Nationwide LEPC Survey, George Washington University Department of Public Administration, Washington, DC, 1994.

[2] R. Andrews, Local planners and hazardous materials, J. Am. Plann. Assoc. 53 (1987) 3-5.

[3] M. Baram, P. Dillon, B. Ruffle, Managing Chemical Risks, Lewis Publishers, Boca Raton, FL, 1992.

[4] P. Berman, Thinking about programmed and adaptive implementation, in: H. Ingram, D. Mann (Eds.), Why Policies Succeed or Fail, Sage, Beverly Hills, CA, 1980, pp. 83-109.

[5] L.W. Bierlein, The problem of complexity, in: R. Scanlon (Ed.), Hazardous Materials, Hazardous Wastes, International City Management Association, Washington, DC, 1987, pp. 12-23.

[6] T. Birkland, Natural disasters as focusing events: policy communities and political response, Int. J. Mass Emergencies Disasters 14 (1996) 221-243.

[7] F. Burkhart, Journalists as bureaucrats: perceptions of social responsibility media roles in local emergency planning committees, Int. J. Mass Emergencies Disasters 9 (1991) 75-87.

[8] Chemical Manufacturers Association, Community Awareness and Emergency Response: Program Handbook, Chemical Manufacturers Association, Washington, DC, 1985.

[9] Chemical Manufacturers Association, Process Safety Management: Control of Acute Hazards, Chemical Manufacturers Association, Washington, DC, 1985. 
[10] Chemical Manufacturers Association, Site Emergency Response Planning, Chemical Manufacturers Association, Washington, DC, 1986.

[11] Chemical Manufacturers Association, Community Emergency Response Exercises, Chemical Manufacturers Association, Washington, DC, 1986.

[12] Chemical Manufacturers Association, Emergency Warning Systems, Chemical Manufacturers Association, Washington, DC, 1987.

[13] Chemical Manufacturers Association, Risk Communication, Risk Statistics \& Risk Comparisons, Chemical Manufacturers Association, Washington, DC, 1988.

[14] Chemical Manufacturers Association, Communicating Title III, Chemical Manufacturers Association, Washington, DC, 1990.

[15] C. Chess, A. Seville, M. Greenberg, M. Tamuz, From Crisis to Credibility, Environmental Communication Research program, Rutgers University, New Brunswick, NJ, 1991.

[16] K. Chinander, P. Kleindorfer, H. Kunreuther, Compliance strategies and regulatory effectiveness of performance-based regulation of chemical accident risks, Risk Anal. 18 (1998) 135-144.

[17] Citizens Fund, Manufacturing Pollution: A Survey of the Nation's Toxic Polluters, Citizens Fund, Washington, DC, July 1991.

[18] W.D. Conn, R. Rich, W. Owens, Communicating Hazardous Materials Risk Information at the Local Level, Virginia Polytechnic Institute Center for Environmental and Hazardous Materials Studies, Blacksburg, VA, 1989.

[19] L. Curran, G. Kizior, A computerized method for reporting SARA Title III Section 313 emissions from a petroleum refinery, J. Hazard. Mater. 31 (1992) 255-275.

[20] T.E. Drabek, Human System Responses to Disaster, Springer, New York, NY, 1986.

[21] T.E. Drabek, The Professional Emergency Manager, University of Colorado Institute of Behavioral Science, Boulder, CO, 1987.

[22] T.E. Drabek, Emergency Management: Strategies for Maintaining Organizational Integrity, Springer, NY, 1990.

[23] C. Faupel, C. Bailey, Contingencies affecting emergency preparedness for hazardous wastes, Int. J. Mass Emergencies Disasters 5 (1988) 265-284.

[24] Federal Emergency Management Agency, Planning Guide and Checklist for Hazardous Materials Contingency Plans-FEMA 10, Federal Emergency Management Agency, Washington, DC, 1981.

[25] Federal Emergency Management Agency, Handbook of Chemical Hazard Analysis Procedures, Federal Emergency Management Agency, Washington, DC.

[26] D.L. Feldman, SARA Title III and community hazards planning, Int. J. Mass Emergencies Disasters 11 (1993) 85-97.

[27] J. Fillo, C. Keyworth, EPCRA: a new era of corporate responsibility and accountability, J. Hazard. Mater. 31 (1992) 219-231.

[28] A.F. Finegold, J. Solyst, Emergency Planning and Community Right to Know Act: A Status of State Actions — 1993, National Governors' Association Washington, DC, 1994.

[29] F. Fire, N. Grant, D. Hoover, SARA Title III, Van Nostrand Reinhold, New York, NY, 1990.

[30] K. Friedman, EPA and SARA Title III, Chem. Eng. Prog. 85 (1989) 18-25.

[31] J.R. Galbraith, Organizational Design, Addison-Wesley, Reading, MA, 1977.

[32] D. Gillespie, C. Streeter, Conceptualizing and measuring disaster preparedness, Int. J. Mass Emergencies Disasters 5 (1987) 155-176.

[33] D. Gillespie, R. Colignon, M. Mahasweta, S. Banerjee, S. Murty, M. Rogge, Partnerships for Community Preparedness, University of Colorado Natural Hazards Research and Applications Information Center, Boulder, CO, 1993.

[34] D.L. Gladstein, Groups in context: a model of task group effectiveness, Admin. Sci. Quart. 29 (1984) 499-517.

[35] M. Hunt, How Science Takes Stock: The Story of Meta-Analysis, Russell Sage Foundation, New York, NY, 1997.

[36] K. Hurley, A. Goins, Automating SARA Title III reporting, Pollut. Eng. 2 (1990) 110-116.

[37] J. Kartez, Community planning for industrial risk: a Title III research agenda, Ind. Crisis Quart. 3 (1989) $61-75$. 
[38] J. Kartez, LEPC Roles in Toxic Hazards Reduction: Implementing Title III's Unwritten Goals, Texas A\&M Hazard Reduction and Recovery Center, College Station, TX, 1992.

[39] J. Kartez, M.K. Lindell, Planning for uncertainty: the case of local disaster planning, J. Am. Plann. Assoc. 53 (1989) 487-498.

[40] J. Kartez, M.K. Lindell, Adaptive planning for community disaster response, in: R. Silves, W. Waugh (Eds.), Cities and Disaster, Charles C. Thomas Publishers, Springfield, IL, 1990, pp. 3-31.

[41] C. Keyworth, D. Smith, Emergency notification under SARA Title III: impacts on facility emergency planning, J. Hazard. Mater. 31 (1992) 241-253.

[42] J. Labadie, Problems in local emergency management, Environ. Manage. 8 (1984) 489-494.

[43] D. Leesak, Hazardous Materials: Strategies and Tactics, Prentice-Hall, Upper Saddle River, NJ, 1999.

[44] M. Levin, D. Spence, SARA Title III: pitfalls and practicalities, J. Air Waste Manage. Assoc. 39 (1989) 29-33.

[45] M.K. Lindell, Are Local Emergency Preparedness Committees effective in developing community disaster preparedness, Int. J. Mass Emergencies Disasters 12 (1994) 159-182.

[46] M.K. Lindell, Assessing emergency preparedness in support of hazardous facility risk analyses, J. Hazard. Mater. 40 (1995) 297-319.

[47] M.K. Lindell, C.J. Brandt, Climate quality and climate consensus as mediators of the relationship between organizational antecedents and outcomes, J. Appl. Psychol. (2001) in press.

[48] M.K. Lindell, M.J. Meier, Effectiveness of community planning for toxic chemical emergencies, J. Am. Plann. Assoc. 60 (1994) 222-234.

[49] M.K. Lindell, R.W. Perry, Behavioral Foundations of Community Emergency Planning, Hemisphere Press, Washington, DC, 1992.

[50] M.K. Lindell, R.W. Perry, Addressing gaps in environmental emergency planning, J. Environ. Plann. Manage. 39 (1996) 531-545.

[51] M.K. Lindell, R.W. Perry, Earthquake impacts and hazard adjustment by acutely hazardous materials facilities following the Northridge earthquake, Earthquake Spectra 14 (1998) 285-299.

[52] M.K. Lindell, D.J. Whitney, Effects of organizational environment, internal structure and team climate on the effectiveness of Local Emergency Planning Committees, Risk Anal. 15 (1995) 439-447.

[53] M.K. Lindell, C.S. Clause, C.J. Brandt, R.S. Landis, The relationship between organizational context and job analysis task ratings, J. Appl. Psychol. 83 (1998) 769-776.

[54] M.K. Lindell, D.J. Whitney, C.J. Futch, C.S. Clause, Multi-method assessment of organizational effectiveness in a local emergency planning committee, Int. J. Mass Emergencies Disasters 14 (1996) $195-220$.

[55] M.K. Lindell, D.J. Whitney, C.J. Futch, C.S. Clause, The Local Emergency Planning Committee, in: R. Silves, W. Waugh (Eds.), Disaster Management in the US and Canada, Charles C. Thomas Publishers, Springfield, IL, 1996, 234-249.

[56] M.K. Lindell, D.J. Whitney, C.J. Futch, C.S. Clause, W.M. Rogers, First Year Feedback Report to the Michigan SERC, Michigan State University Department of Psychology, East Lansing, MI, 1994.

[57] M.K. Lindell, D.J. Whitney, C.J. Futch, C.S. Clause, W.M. Rogers, First Year Feedback Report to the Indiana SERC, Michigan State University Department of Psychology, East Lansing, MI, 1994.

[58] M.K. Lindell, D.J. Whitney, C.J. Futch, C.S. Clause, W.M. Rogers, First Year Feedback Report to the Illinois SERC, Michigan State University Department of Psychology, East Lansing, MI, 1994.

[59] M.K. Lindell, D.J. Whitney, C.J. Futch, C.S. Clause, W.M. Rogers, Organizational Correlates of Effectiveness in Local Emergency Planning Organizations, Michigan State University Department of Psychology, East Lansing, MI, 1995.

[60] G. Malich, M. Braun, P. Loullis, C. Winder, Comparisons of regulations concerning hazardous substances from an international perspective, J. Hazard. Mater. 62 (1998) 143-159.

[61] A. Matheny, B. Williams, Rethinking participation: assessing Florida's strategy for siting hazardous waste disposal facilities, in: C. Davis, J. Lester. (Eds.), Dimensions of Hazardous Waste Politics and Policy, Greenwood Press, New York, NY, 1988, pp. 37-52.

[62] P. May, Reconsidering policy design: policies and publics, J. Public Policy 11 (1990) 187-206.

[63] P. May, W. Williams, Disaster Policy Implementation, Plenum Press, New York, NY, 1987.

[64] Michigan Emergency Management Division, Haz/Mat Response Planning Workbook, EMD PUB-301 (revised), Lansing, MI, 1987. 
[65] Michigan Emergency Management Division, Warning, Evacuation \& In-Place Protection Handbook, EMD PUB-304, Lansing, MI, 1994.

[66] Michigan Emergency Management Division, LEPCs: Organizing for Success, EMD PUB-305, Lansing, MI, 1994.

[67] D. Mickunas, V. Kansal, R. Turpin, Ambient monitoring of a SARA Title III facility using the TAGA 6000E MS/MS, J. Hazard. Mater. 43 (1995) 45-54.

[68] D. Mileti, Human adjustment to the risk of environmental extremes, Sociol. Social Res. 64 (1980) $327-347$.

[69] M. Miner, Good corporate citizenship and SARA reporting, Pulp and Paper 71 (1997) 43-44.

[70] W. Morehouse, Citizen, worker and state: the search for new paradigms in coping with industrial crises, Ind. Crisis Quart. 1 (1987) 22-33.

[71] V. Musselman, Emergency Planning and Community Right to Know, Van Nostrand Reinhold, New York, NY, 1989.

[72] National Governors Association, The Emergency Planning and Community Right to Know Act, National Governors Association, Washington, DC, 1990.

[73] National Response Team, Hazardous Materials Emergency Planning Guide NRT-1, National Response Team, Washington, DC, 1987.

[74] National Response Team, Criteria for Review of Hazardous Materials Emergency Plans NRT-1a, National Response Team, Washington, DC, 1988.

[75] National Response Team, Developing a Hazardous Materials Exercise Program NRT-2, National Response Team, Washington, DC, 1990.

[76] National Safety Council, The Community Partnership: A Hazardous Materials Planning Guide for Citizens, Local Government, Industry and Commerce, National Safety Council, Chicago, IL, 1987.

[77] National Safety Council, User's Manual for CAMEO: Computer-Aided Management of Emergency Operations, National Safety Council, Chicago, IL, 1995.

[78] M. O’Hare, Information strategies and regulatory surrogates, in: E. Bardach, R. Kagan (Eds.), Social Regulation: Strategies for Reform, Transaction Books, New Brunswick, NJ, 1982, pp. 391-400.

[79] R.W. Perry, The Social Psychology of Civil Defense, Heath-Lexington Books, Lexington, MA, 1982.

[80] R.W. Perry, Diffusion theories, in: E. Borgatta, M. Borgatta (Eds.), The Encyclopedia of Sociology, MacMillan, New York, NY, 1991, pp. 487-492.

[81] R.W. Perry, M.K. Lindell, M.R. Greene, Evacuation Planning and Emergency Management, Heath-Lexington Books, Lexington, MA, 1991.

[82] S. Porter, J. Wettig, Policy issues on the control of major accident hazards and the new Seveso II directive, J. Hazard. Mater. 65 (1999) 1-14.

[83] C.S. Prater, M.K. Lindell, The politics of hazard mitigation, Nat. Hazards Rev. 1 (2000) 73-82.

[84] J. Prestby, A. Wandersman, An empirical exploration of a framework of organizational viability, J. Appl. Behav. Sci. 21 (1985) 287-305.

[85] K.M. Rest, Implementing Public Policy at the Local Level, Boston University Doctoral Dissertation, Boston, MA, 1990.

[86] R. Rich, W. Conn, W. Owens, Strategies for effective risk communication under SARA Title III, Environ. Prof. 14 (1992) 228-237.

[87] R. Rich, W. Conn, W. Owens, Indirect regulation of environmental hazards through the provision of information to the public: the case of SARA Title III, Policies Stud. J. 21 (1993) 16-34.

[88] P. Rossi, J. Wright, E. Weber-Burdin, M. Pietras, W. Diggins, Natural Hazards and Public Choice, Academic Press, New York, NY, 1982.

[89] S.K. Schneider, Governmental response to disasters: the conflict between bureaucratic procedures and emergent norms, Public Admin. Rev. 52 (1992) 135-145.

[90] R. Schwab, Environmental federalism, Resources 92 (1988) 6-8.

[91] P. Shabekoff, Industry to give vast new data on toxic perils, New York Times 14 (1988) 1-16.

[92] S. Sherry, R. Purin, Disclosure information systems, in: R. Scanlon (Ed.), Hazardous Materials, Hazardous Wastes: Local Management Options, International City Management Association, Washington, DC, 1987, pp. 51-57.

[93] K. Smith, Building trust in your community, Tappi J. 76 (1993) 266-267.

[94] J. Solyst, M. St. Amand, Emergency Planning and Community Right to Know Act: A Status of State Actions - 1991, National Governors' Association, Washington, DC, 1991. 
[95] J. Solyst, M. St. Amand, Emergency Planning and Community Right to Know Act: A Status of State Actions — 1992, National Governors' Association, Washington, DC, 1992.

[96] D. Stone, Policy Paradox, W.W. Norton and Company, New York, NY, 1997.

[97] S. Sutphen, V. Bott, Issue salience and preparedness as perceived by city managers, in: R. Silves, W. Waugh (Eds.), Cities and Disaster, Charles C. Thomas Publishers, Springfield, IL, 1990, pp. 133-153.

[98] V. Sutton, Perceptions of Local Emergency Planning Committee Members' Responsibility for Risk Communication and a Proposed Model Risk Communication Program for Local Emergency Planning Committees Under SARA Title III, University of Texas Doctoral Dissertation, Austin, TX, 1990.

[99] U.S. Department of Transportation, 2000 North American Emergency Response Guidebook, U.S. Department of Transportation, Washington, DC, 2000.

[100] U.S. Environmental Protection Agency, Chemical Emergency Preparedness Program: Interim Guidance, U.S. Environmental Protection Agency, Washington, DC, 1985.

[101] U.S. Environmental Protection Agency, Technical Guidance for Hazards Analysis: Emergency Planning for Extremely Hazardous Substances, U.S. Environmental Protection Agency, Washington, DC, 1987.

[102] U.S. Environmental Protection Agency, Risk Communication about Chemicals in Your Community, U.S. Environmental Protection Agency, Washington, DC, 1989.

[103] U.S. Environmental Protection Agency, Successful Practices in Title III Implementation OSWER-90-006, U.S. Environmental Protection Agency, Washington, DC, 1990.

[104] U.S. Environmental Protection Agency, Bibliography of Materials on the Emergency Planning and Community Right to Know Act (Title III of SARA) OSWER-90-006, U.S. Environmental Protection Agency, Washington, DC, 1990.

[105] US Environmental Protection Agency, SARA Title III Fact Sheet, Environmental Protection Agency, Washington, DC, 1993.

[106] U.S. General Accounting Office, Chemical Emergencies: Preparedness for and Response to Accidental Chemical Air Releases GAO/RCED-86-117-R, U.S. General Accounting Office, Washington, DC, 1986.

[107] U.S. Nuclear Regulatory Commission, Planning Basis for the Development of State and Local Government Radiological Emergency Response Plans in Support of Light Water Nuclear Power Plants, Nuclear Regulatory Commission, Washington, DC, 1978.

[108] U.S. Nuclear Regulatory Commission, Criteria for Preparation and Evaluation of Radiological Emergency Response Plans and Preparedness in Support of Nuclear Power Plants, Nuclear Regulatory Commission, Washington, DC, 1980.

[109] A. Van de Ven, A. Delbecq, The effectiveness of Nominal, Delphi and Interacting group decisions, Acad. Manage. J. 17 (1974) 605-621.

[110] D.J. Whitney, M.K. Lindell, Member commitment and participation in local emergency planning committees, Policy Stud. J. (2001) in press.

[111] R. Wolensky, E. Miller, The everyday versus the disaster role of public officials: citizen and official definitions, Urban Affairs Quart. 16 (1981) 483-504. 